\title{
Bonding and Aromaticity in Electron-Rich Boron and
}

\section{Aluminum Clusters}

\author{
Cina Foroutan-Nejad*
}

Institute of Organic Chemistry, Polish Academy of Sciences, Kasprzaka44/52, 01-224,

Warsaw, Poland

Email: cforoutan-nejad@icho.edu.pl 

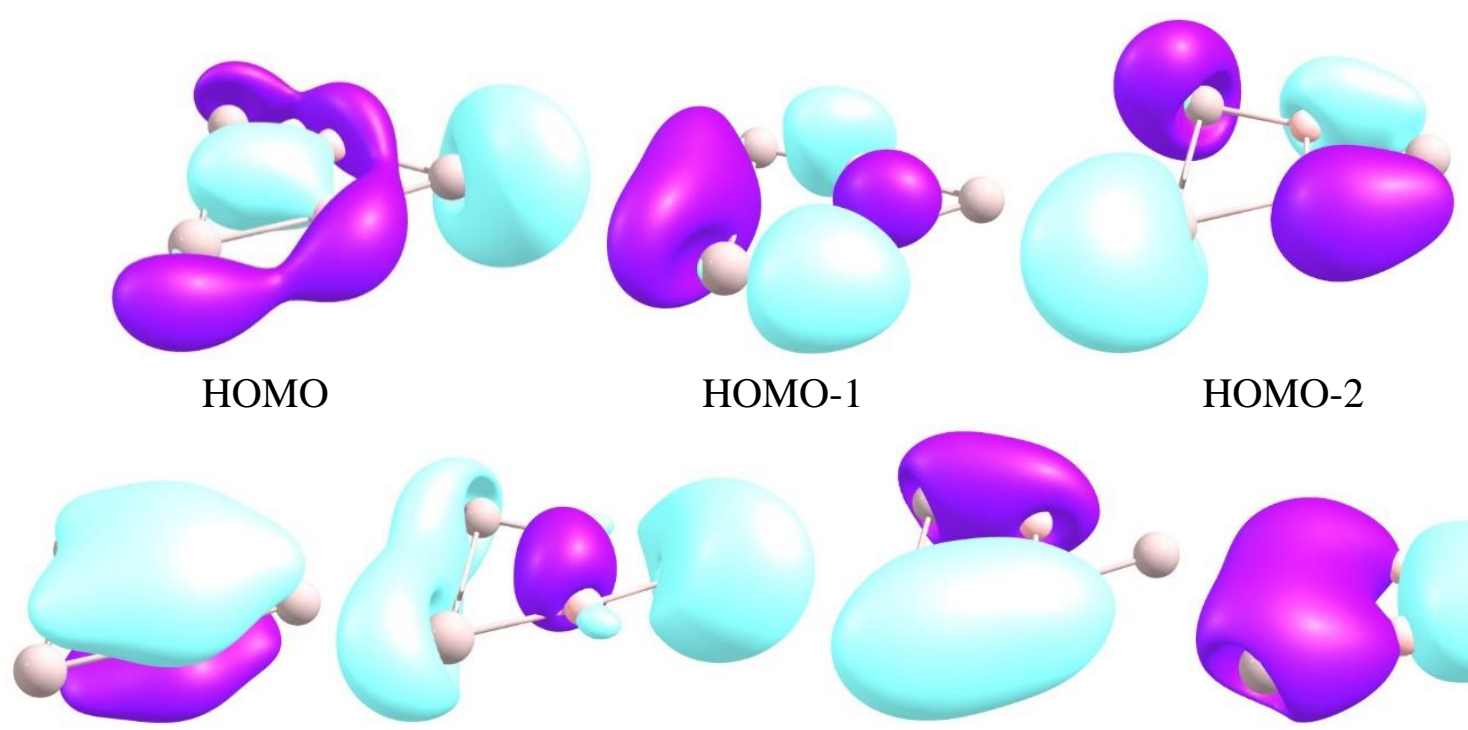

HOMO-3
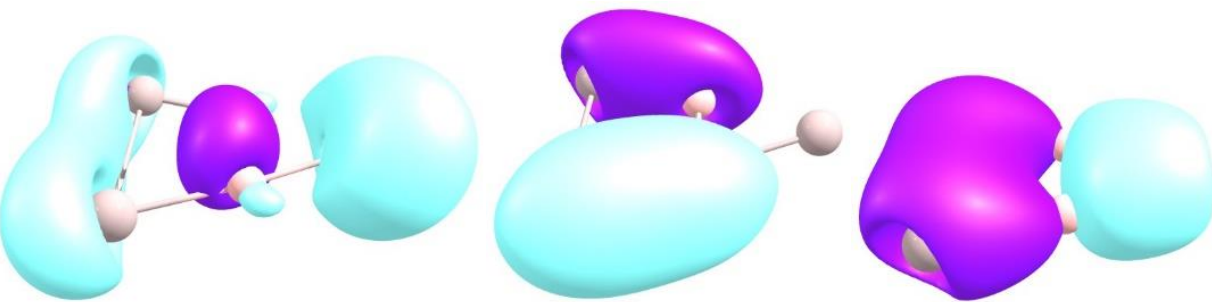

HOMO-4

HOMO-5

HOMO-6

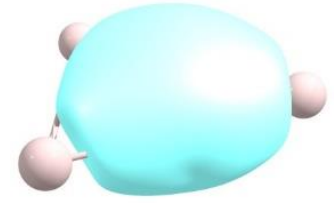

HOMO-7

FIGURE S1. CMOs of $\mathrm{B}_{2} \mathrm{Al}_{3}{ }^{-}$cluster.

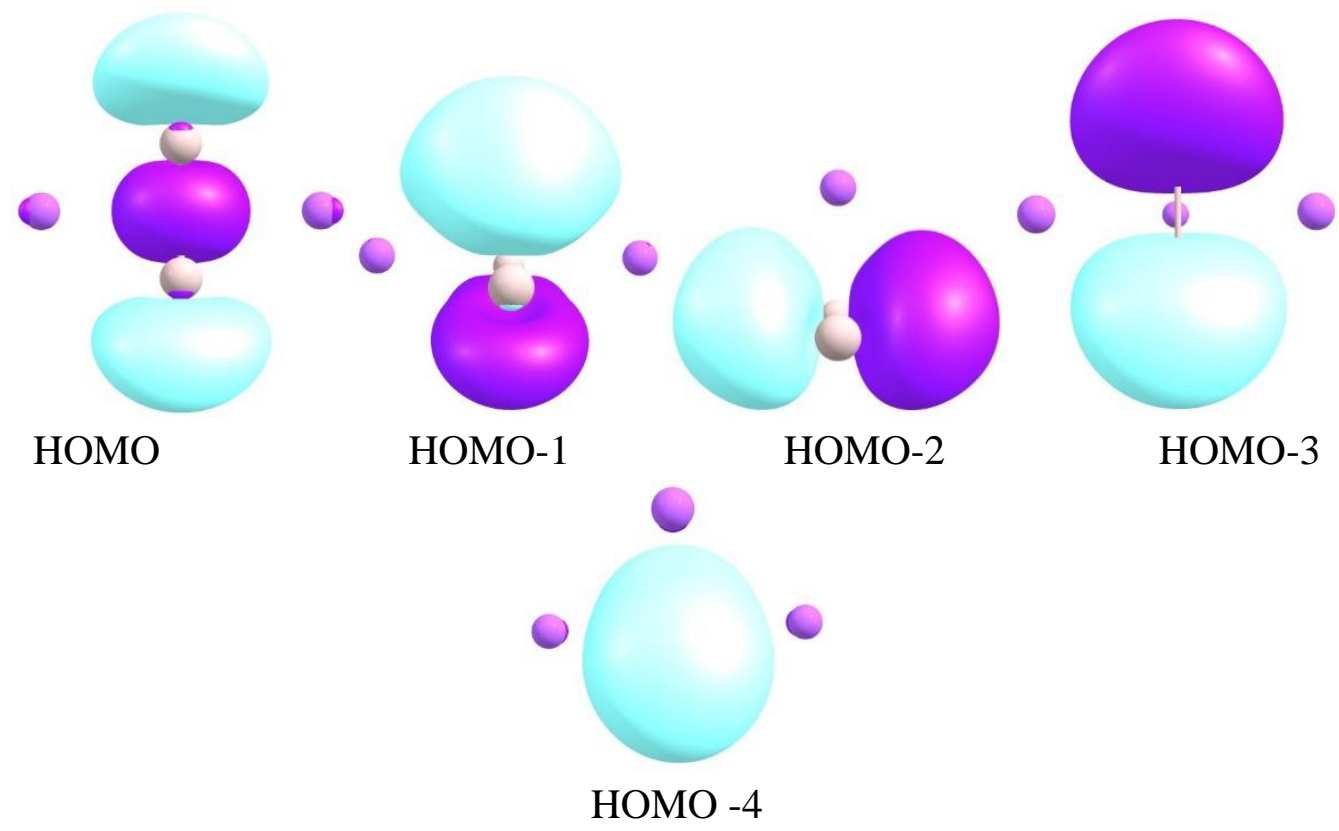

FIGURE S2. CMOs of $\mathrm{Na}_{3} \mathrm{Al}_{2}^{-}$cluster. 


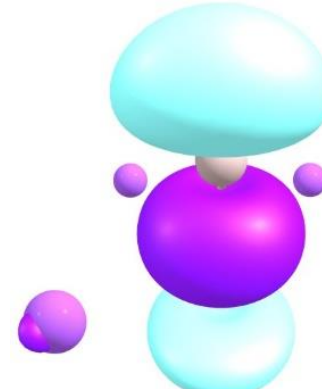

HOMO

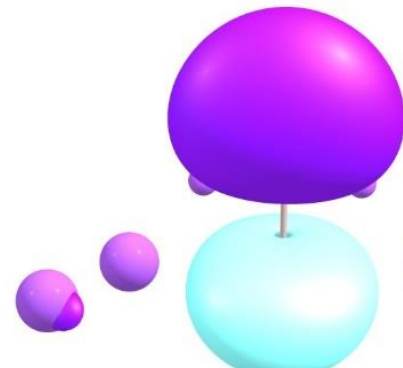

HOMO-1

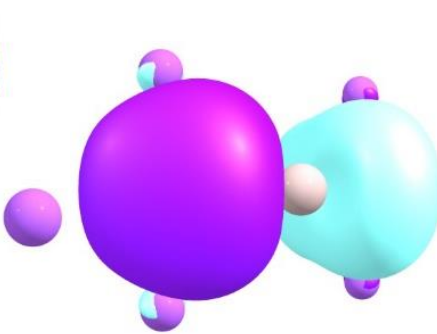

HOMO-2

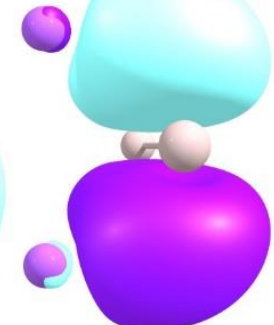

HOMO-3

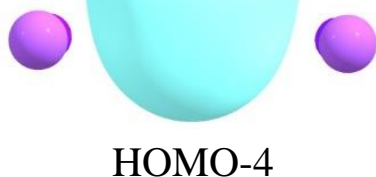

FIGURE S3. CMOs of $\mathrm{Na}_{4} \mathrm{Al}_{2}$ cluster. 